\title{
RECONSTRUCTION OF FRACTURED PERMA- NENT INCISORS IN SCHOOLCHILDREN USING LAMINATE VENEERS (REVIEW)
}

\author{
Ani Belcheva \\ Department of Pediatric Dentistry, Faculty of Dental Medicine, \\ Medical University, Plovdiv, Bulgaria
}

\section{SUMMARY:}

Crown fractures as a part of traumatic injuries are common among schoolchildren. They create serious functional, esthetic and psychological problems. The clinicians must deal with sometimes small patient's age, need of high esthetics in the front part and the choice of exact treatment plan. Repeated reconstructions are needed in many cases because of compromised results as time passed by. Achievement of promising restoration that preserves its esthetics and strength is the greatest desire for both children and their parents.

In this review are collected data for the usage of laminate veneers for restoring fractured incisors in schoolchildren.

A critical analysis of proposed from different authors improvements and objections has been made. These methods summarize succession in the right therapeutic approach.

Key words: veneers, crown fractures, permanent teeth

Aim of this study is to discuss the available dental literature concerning reconstruction of fractured permanent incisors using laminate veneers.

In the last 20 years dentists manufacture veneers to the teeth using different techniques for corrections of esthetic problems. The veneers are divided in three groups according to the materials and techniques applied:
1. direct composite veneers

2. direct-indirect composite veneers and preformed acryl laminates

3. indirect (laboratory made) acryl, composite, porcelain and glass-ceramic veneers

\section{- Advantages and disadvantages}

The clinicians prefer and recommend definite kind of veneer according to the clinical case. Most often cited in the literature advantages and disadvantages of the veneers are shown on table 1 .

Introduction of enamel etching technique and elaboration of hybrid and microfilled composite resin materials gives opportunity for more conservative restoration of fractured teeth connected with application of minimal tooth preparation. In 1975 the first porcelain veneers have been placed after testament of the connection with tooth structures (16). Development of the adhesive systems leads to creation of more stabile linkage between bonding surfaces and tooth structures. $(4,6)$.

\section{- Indications}

Indications for utilization of veneers are pretty large. There are evidences for their usage in tooth fractures, diastema, teeth with malformations, change of position, discolorations (4). Veneers are indicated in restoration of fractured permanent teeth at children for strength improvement and achievement of satisfied esthetics (11).

Table 1. Advantages and disadvantages of different kinds veneers, utilized for restoration of permanent teeth

\begin{tabular}{|l|l|l|}
\hline \multicolumn{1}{|c|}{ veneers } & \multicolumn{1}{|c|}{ advantages } & \multicolumn{1}{c|}{ disadvantages } \\
\hline Direct composite veneer & - available for all dentists & - technical difficulties \\
& - conservative approach & - requires clinical experience \\
& - excellent esthetics & - unsuitable for teeth with high \\
& - excellent gingival reply & discoloration \\
& - easy reparation & \\
\hline & - acceptable price & \\
\hline
\end{tabular}




\begin{tabular}{|l|l|l|}
\hline Indirect porcelain veneer & $\begin{array}{l}\text { - conservative approach } \\
\text { - excellent esthetics } \\
\text { - very good gingival reply }\end{array}$ & $\begin{array}{l}\text { - requires two appointments } \\
\text { - requires more preparation } \\
\text { - technical difficulties } \\
\text { - difficult reparation } \\
\text { - high price }\end{array}$ \\
\hline Direct-indirect composite veneer & $\begin{array}{l}\text { - conservative approach } \\
\text { - excellent esthetics } \\
\text { - excellent gingival reply } \\
\text { - complete polymerization } \\
\text { - easy reparation } \\
\text { - acceptable price }\end{array}$ & $\begin{array}{l}\text { - requires technical skills } \\
\text { - requires prolonged time } \\
\text { - requires extra appliances }\end{array}$ \\
\hline
\end{tabular}

\section{- Tooth preparation}

Vestibular surface

The choice for tooth preparation depends on the material used, extent of discoloration or shape changes as well as the correlation between upper and lower jaw.

In utilization of composite veneers vestibular tooth preparation is minimal $(0,5-0,75 \mathrm{~mm}$ reduction depth) and extends in the enamel borderlines $(3,8,10,17)$. Some authors modify this technique when tooth structures need deeper preparation $(6,7,9)$.

In utilization of porcelain veneers according to the first data the teeth remained intact. Even now some authors do not recommend tooth preparation $(17,19)$. According to the contemporary literature most satisfied results are performed when the preparation is measured, removing hard tissue in two plates - vestibule-gingival $(0,5-0,75 \mathrm{~mm})$ and vestibule -incisal (1-1,2 мм) $(14,17,19)$.

\section{Gingival margin}

Preparation design for direct and indirect veneers most often finishes with chamfer edge gingival and interproximal $(17,19)$. Thus enough space is ensured to represent all color features of natural teeth.

In the past gingival margin has been placed $0,5-1 \mathrm{~mm}$ subgingivaly. The contemporary tendencies report favorable gingival reply when the margins of tooth preparation are placed to margo gingivalis $(14,17,19)$.

In the past it has been claimed that tooth preparation for veneers should remain in the enamel (6). With the dynamic improvement of bonding to dentin it is acceptable the margins of tooth preparation to finish in dentin $(8,14)$. This fact vastly extended clinical cases in which to put successfully veneers to the teeth. It should also be mentioned that even best adhesive materials can not compensate wrong preparation. When the preparation margins include the cement the followed microleakage can influence veneer's retention (8).

Incisal edge

According to Walls et al. there are four basic preparation designs for incisal edge (fig. 1) (20). The influence of these preparations upon veneers' retention has been examined through the years. According to the investigations made there is no need for incisal preparation at direct composite veneers, except in cases when veneers are used to provide incisal guidance. In this case it is necessary to ensure preparation form strong enough to prevent fracture of separate segments. The incisal edge should be reduced with $1 \mathrm{~mm}$ and the preparation to finish lingual with enamel bevel (10). Bevel's width depends on the retention necessary for neutralization of applied from incisal guidance force (10).

Preparation of incisal edge for porcelain veneers should not exceed $2 \mathrm{~mm}$, as wider porcelain thickness can fracture the veneer.

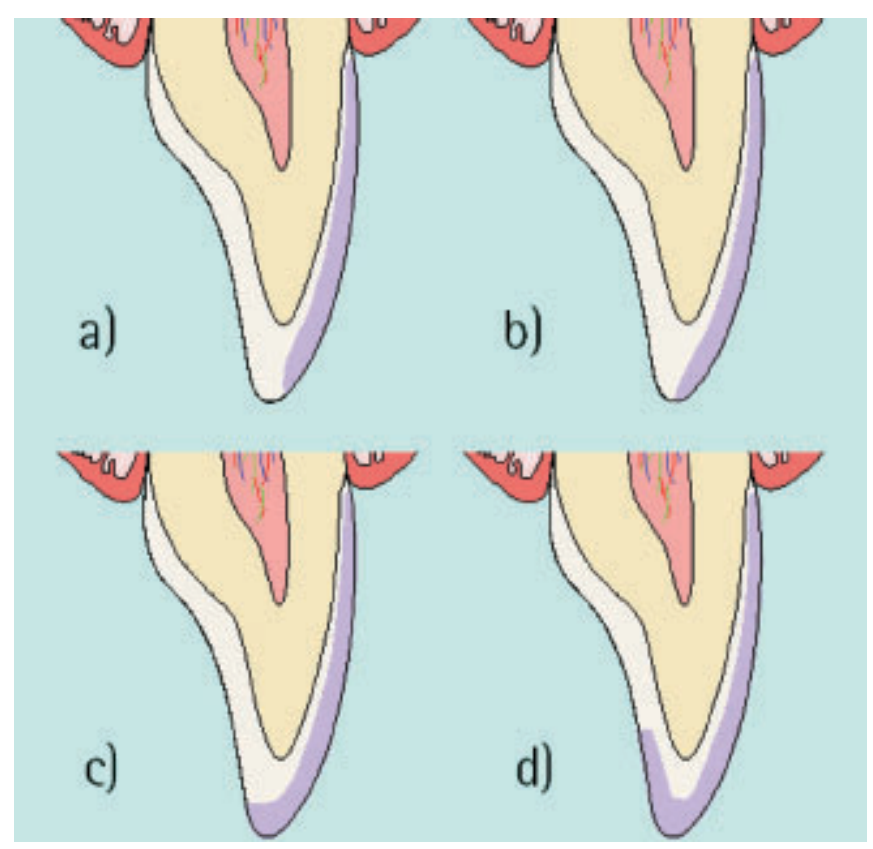

Fig. 1. Appearance preparation of incisal according to Walls et al.

a) "Window" preparation, the veneer is situated close to but not up to the incisal edge;

b) "Feather" preparation, the veneer is taken up to the height of the incisal edge but the edge is not reduced;

c) "Beveled" preparation, a buco-palatal bevel is 
prepared across the full width of the preparation and there is some reduction of the incisal edge;

d) Preparation of "incisal overlap", in which the incisal edge is reduced and the preparation extended palatal

Very important conclusions are made in the study of Magne and Duglas. The authors point out significant strength improvement of restored with veneers fractured incisors when replacing the missing tooth structures with composite resin for optimization of incisal edge preparation (12). Other investigations accept the fact that composite resin restoration should be made not more than 2 to 3 years before veneer placement, in order to reduce the negative influence upon traction resistance (7).

Lingual overlap of the preparation margins starts an argument between clinicians. In one of his investigations Magne (13) develops experimental scientific setting and optimizes preparation design with the principles of engineering mechanics. He strives for proposing the best decision for neutralizing of the inherent in techniques and materials loading. The conclusions of this investigation show most satisfied results in incisal reduction up to $2 \mathrm{~mm}$, without lingual overlap. This preparation design diminishes risk for incisal fracture as well as the loading that stand both tooth and material (5).

\section{Proximal finishing lines}

It suggested by some authors that proximal finishing lines should not extend beyond contact point in the incisal third of the tooth. It means to preserve the contact point with the adjacent teeth $(8,20)$.

According to the published in the literature data when the preparation has sharp edges this leads to concentration of different forces on that place and cracks and fractures of the veneer may occur $(3,8,15)$. Smooth and rounded internal angles of the preparation will help to reduce stresses at the preparation edges and prevents from fractures $(10,20)$.

Every reduction design for veneer is based on certain principles that help fracture resistance Adhesive bonding of veneers to tooth structures ensures the strength of the whole complex. Thickness up to $2 \mathrm{~mm}$ also diminishes fracture probability. It is necessary to achieve adequate incisal guidance which exists normally or is provided by planned tooth preparation (13).

Composite veneers can be made directly on the tooth or direct-indirectly with the help of plaster models and extra polymerization light box. Lack of laboratory procedures facilitates the method and makes it preferable at small children (10). Porcelain veneers are made by dental technician in laboratory conditions (20).

\section{- Placement and luting}

Before placement tooth surfaces are thoroughly cleaned with pumice. Placement and luting of direct composite veneers is made after etching of the enamel and usage of adhesive system. The procedure follows up the manufacturer's instructions as a clinical protocol.

Placement of porcelain veneers begins also with cleaning of the surfaces. The porcelain veneer is tried in on the dental surface by the help of specific paste that is colored in some shades. The paste should match the tooth color. It is possible to do this procedure with the luting resin (20). Porcelain veneers can be fixed with dual cement which hardening is catalyzed chemically and by luting activation. Acid etching with hydrofluoric acid, washing and drying is performed on both tooth surface and internal part of the veneer. After that prior to placement of the veneer to its internal surface is applied a silane-coupling agent. Dentine bonding agent is applied and the veneer is loaded with luting agent. The excess of resin round the periphery of veneer can best be removed at that stage with metal instrument. The suggested cure time is at about $60 \mathrm{sec}$. Most important in performing the adhesive technique is the moisture control. Placement of rubber dam and retraction cord can be helpful in prevention of contamination (20).

Direct-indirect veneers are placed and luted in the same way as porcelain ones without applying of silane coupling agent (10)

\section{- Finishing and polishing}

The last stage is finishing and polishing the margins. Finishing and polishing contribute for smooth and harmonious transition from tooth to restoration. It is important to eliminate any occlusal interference (20). For this purpose a system of carbide and diamond burs, polishing disks (Soflex discs) and polishing pastes are used.(9)

\section{- Prognoses}

Composite veneers can stand unchanged from 2 up to 13 years in good hygiene and minimal harmful habits (9). Microfilled veneers tend to wear with time and loose their gloss (2). Some resin materials have included small bubbles that can appear on the surface and fill with food or plaque stains. That leads to early repair of the veneer (18).

Direct-indirect veneers have long live longevity than the direct veneers. Their strength and abrasion stability is improved and the polymerization shrinkage is minimal (10).

Composite veneers can be easily repaired when occurring some of the problems mentioned. That makes them economically favorable (10).

Reconstruction of fractured children's teeth with composite veneers improves esthetics and preserves tooth structures. Some authors place them as temporary restoration until development completion and replace them with porcelain veneers (20). According to a clinical study of Welbury, made on 289 composite veneers of child and adolescence, followed up for 3 years, the average strength of the veneers is 35,6 month (21).

Porcelain veneers are with best esthetic and mechanical properties and show low fracture degree. Unlike 
composite veneers they can not be repaired $(1,3)$. Porcelain veneers do not chance their color with time and have no leakage of water soluble dyes. Marginal adaptation and luting technique pay an important role for the degree and time after which a marginal discoloration will appear (15). Patient's hygiene is also of great importance. A serious disadvantage of porcelain veneers is their high price (8).

\section{CONCLUSIONS}

Elaboration of veneers on teeth with compromised esthetics and function is a conservative method that improves appearance, modifies contour without reducing hard tissues as for the whole tooth crown. In that context the method is minimal invasive and indicated for children. Even in the period of growth and development, when children are at high risk for tooth trauma, fractured teeth can be successfully restored with minimal tooth preparation utilizing composite veneers. Knowledge of the methods for making and applying composite or porcelain veneers for restoration of fractured permanent teeth at schoolchildren is useful advantage of dental doctor for mastering the esthetic and functional problems of the young patients.

\section{REFERENCE}

1. Alonge OK, Nerendran S, Williamson DD. Prevalence of fractured incisor teeth among children in Harris County, Texas. Dent Traumatol 2001; 17: 218-221.

2. AlSarheed M, Bedi R, Hunt NP. Traumatized permanent teeth in 11-16year-old Saudi Arabian children with a sensory impairment attending special schools. Dent Traumatol 2003; 19: 123125.

3. Bruton PA, Aminian A, Wilson NH. Tooth preparation techniques for porcelain laminate veneers. Br Dent J 2000; 5: 260-262.

4. Calamia JR. Clinical evaluation of etched porcelain veneers. Am J Dent 1989; 2: 9-15.

5. Castelnuovo J, Tjan AH, Phillips K, Nicholls JI, Kois JC. Fracture load and mode of failure of ceramic veneers with different preparations. J Prosthetic Dent 2000; 83: 171-180.

6. Christensen GJ. Veneering of teeth. State of the art. Dent Clin North Am 1985; 29: 373-391

7. Dhur VB, Lloyd CH. The fracture toughness of repaired composite. J Oral Rehabil 1986; 13: 413-421.

8. Dumfahrt H. Porcelaine laminate veneers. A retrospective evaluation after 1-10 years. I. Clinical Procedure. Int J Prosthodont 1999; 12: 505-513.

9. Kreulen CM, Cruegers $\mathrm{NH}$, Meijering AC. Meta-analysis of anterior veneer restorations in clinical studies. J Dent 1998; 26: 345-53.

10. Larson TD. The use of a direct bonded microfilled composite resin veneer. JADA 1987; 115: 449-53.

11. Magne P, Douglas WH. Cumulative effects of successive restorative procedures on anterior crown flexure: intact versus veneered incisors. Quintessence Int 2000;31:5-18.

12. Magne P, Douglas WH. Interdental design of porcelain veneers in the presence of composite fillings: finite element analysis of composite shrinkage and thermal stresses. Int $J$ Prosthodont. 2000; 13: 117-124.

13. Magne P, Douglas WH. Optimization of resilience and stress distribution in porcelain veneers for the treatment of crown-fractured incisors. Int J Periodontics Restorative Dent. 1999; 19: 543-553.

14. Padbury Jr A, Eber R, Wang HL. Interactions between the gingiva and the margin of restorations. J Clin Periodontal 2003; 30: 379-385.

15. Peumans M, Van Meerbeek B,
Lambrechts P, Vanherle G. Porcelain veneers: a review of the literature. J Dent 2000; 189: 163-177.

16. Rochette AL. A ceramic restoration bonded by etched enamel and resin for fractured incisors. J Prosthetic Dent 1975; 33: 287-293.

17. Shaini FJ, Shortall AC, Maruis PM. Clinical performance of porcelain laminate veneers. A retrospective evaluation over a period of 6.5 years. J Oral Rehabil 1997; 24:553-559.

18. Shortall AC, Uctasli S, Maruis PM. Fracture resistance of anterior, posterior and universal light activated composite restoratives. Oper Dent 2001; 26: 87-96.

19. Troedson M, Derand T. Effect of margin design, cement polymerization, and angle of leading on stress in porcelain veneers. J Prosthet Dent 1999; 82: 518-524.

20. Walls AWG, Steele JG, Wassell. Crowns and other extra-coronal restorations: Porcelain laminate veneers. $\mathrm{Br}$ Dent J. 2002; 193:73-82.

21. Welbury RR. A clinical study of a microfilled composite resin for labial veneers. Pract Periodontics Aesthet Dent. 1996; 8:627-638.

\section{Address for correspondence:}

Dr. Ani Beltcheva, PhD

Department of Pediatric Dentistry, Faculty of Dental Medicine, Medical University, Plovdiv, Bulgaria

E-mail abeltcheva@yahoo.com 